\title{
O ALUNO COM DEFICIÊNCIA NO ENSINO REGULAR NO SÉCULO XXI: INCLUSÃO OU EXCLUSÃO?
}

\author{
Palmira Aparecida de Andrade Souza \\ Mestranda em História pela Universidade Estadual de Goiás - Campus Morrinhos. \\ E-mail: palmiraandradsouza@gmail.com
}

Antônio Carlos Freire Sampaio

LAGEPOP/IG/Universidade Federal de Uberlândia.

\begin{abstract}
RESUMO
A presente pesquisa tem por objetivo fomentar uma discussão sobre o processo de inclusão de alunos deficientes no sistema de ensino regular. Para tanto, foi utilizada pesquisa bibliográfica com base em autores que tratam da temática e pesquisa documental a partir de legislação que regem a inclusão escolar no Brasil. Neste viés, o estudo aponta que um processo de integração de cidadãos numa estrutura física, pedagógica que quase sempre não oferece condições necessárias para acolher os discentes e promover uma igualdade de oportunidade para aprendizagem efetiva. A acessibilidade no Brasil é uma questão que envolve cultura de aceitação e respeito ao direito do deficiente que precisa de recursos físicos apropriados, profissionais capacitados para lidar com cada especificidade. O que acontece é a falta compromisso e atitude do poder público para efetivar o direito de equidade de oportunidades que está na Lei conquistada - LBI - Lei Brasileira de Inclusão. Assim sendo cabe uma consciência coletiva para fazer avançar e valer o direito de igualdade, bem como muitas discussões para ajudar no assunto.
\end{abstract}

Palavras-chaves: Aluno deficiente. Ensino regular. Exclusão.

\section{INTRODUÇÃO}

As inquietações, no exercício da profissão de professora da Disciplina de História, nos ambientes de ensino e aprendizado, que tem aluno deficiente constituem fato. O aluno com deficiência no ensino regular, sendo um dos vieses da inclusão social, é um processo que envolve formação e preparo pedagógico para atender as especificidades de cada um. Não é apenas colocar o deficiente no espaço da sala de aula, sem condições apropriadas, para tentar acompanhar as atividades, hora ou outra adaptadas.

A realidade conhecida é que neste processo "bilateral" ou cultural, se precisa de uma consciência social, um enfrentamento em conjunto para que os excluídos, que são muitos e podem ser prejudicados, devido ao que estamos vivendo neste início de século XXI, com a pandemia da COVID-19 que evidenciou ainda mais a falta de distribuição de renda, o aumento de desemprego e falta de condições para alimentação. Diante de uma crise sanitária, chega a ser utópico pensar numa escola pública inclusiva de fato, haja vista a falta de investimento físico e humano. 
Neste contexto, exposto nos parágrafos anteriores, a realidade descumpre um dos artigos do Estatuto da Pessoa com Deficiência, o "Art. 4" Toda pessoa com deficiência tem direito à igualdade de oportunidades com as demais pessoas e não sofrerá nenhuma espécie de discriminação". (BRASIL, 2015).

As dificuldades são muitas para lidar com a realidade da inclusão social do deficiente em sala de aula "convencional", por vários motivos que podemos enumerar: a falta de capacitação de muitos profissionais da educação, preparo da família, da sociedade. E também dos espaços e obras arquitetônicas que não foram projetadas para atender todos os cidadãos com suas peculiaridades.

Diante do exposto, o objetivo desta pesquisa é provocar uma discussão acerca do processo de inclusão de pessoas com deficiência nas Instituições Escolares convencionais, ou seja, sala de aula do ensino regular, que muito pouco tem a proporcionar, oferecer aos educandos, em termo de acolhimento, recurso especifico de acordo com as especificidades.

Para tanto, a realização deste estudo contou com pesquisa bibliográfica ou de fontes secundárias que abrangem bibliografia já tornada pública, em relação ao tema de estudo publicado em artigos, livros, teses, entre outras (LAKATOS; MARCONI, 2009). Nessa perspectiva, o aporte teórico foi realizado contando com os escritos de Sassaki (2005); Mantoan (2003); Santos e Aureliano (2012).

Também foram utilizadas, como fonte para o trabalho, algumas legislações como da Lei Brasileira de Inclusão da Pessoa com Deficiência - LBI (BRASIL, 2015), Constituição Federal - CF (BRASIL, 1988) e Lei de Diretrizes e Bases da Educação Nacional - LDB (BRASIL, 1996).

\section{ALUNO DEFICIENTE NO ENSINO REGULAR: IMPORTÂNCIA DA INCLUSÃO}

Incluir o deficiente na sala de aula do ensino regular requer uma força tarefa cultural, não só cumprir a lei, as reinvindicações e também começar pela família. Se refletir sobre a história da criança que por muito tempo do ponto de vista histórico não tinha espaço na sociedade. Em casa, ela não tinha voz visto que o deficiente era escondido, pois muitas vezes as famílias tinham receio, vergonha em apresentá-lo para a sociedade.

Conforme Mantoan (2003): 
Na perspectiva inclusiva, suprime-se a subdivisão dos sistemas escolares em modalidades de ensino especial e regular. As escolas atendem às diferenças sem discriminar, sem trabalhar à parte com alguns alunos, sem estabelecer regras específicas para se planejar, para aprender, para avaliar. (MANTOAN, 2003, p. 25).

O direito de ser incluído no ensino regular é preconizado primeiramente pela Constituição Federal de 1988, lei maior do país, que assegura o acesso de todos os alunos na sala de aula do ensino regular. Isso tem levado a uma profunda reflexão sobre o sentido da escola, sobre o seu papel de formador das futuras gerações e sobre o desafio de considerar as diferenças na sala de aula um fator que qualifique e enriqueça o ensino.

É importante compreender que a educação inclusiva está relacionada a um processo de inclusão dos alunos que apresentam necessidades educacionais especiais ou não, na rede comum do ensino em todos os níveis.

Segundo o artigo 205 da Constituição Federal, "a educação, direito de todos e dever do Estado e da família, será promovida e incentivada com a colaboração da sociedade, visando ao pleno desenvolvimento da pessoa, seu preparo para o exercício da cidadania e sua qualificação para o trabalho" (BRASIL, 1988).

Ainda de forma mais direta, o art. 208 e inciso III também da Constituição Federal, asseguram que "o dever do Estado com a educação será efetivado mediante a garantia de: (...) III - atendimento educacional especializado aos portadores de deficiência, preferencialmente na rede regular de ensino" (BRASIL, 1988).

Reforçando a premissa da educação inclusiva, a legislação brasileira conta, além de portarias e decretos, com leis tais como a Lei $\mathrm{n}^{\mathrm{o}}$ 12.796, de 4 de abril de 2013 que altera a Lei 9394/96 de Diretrizes e Bases da Educação Nacional de 1996, e no artigo $4^{\circ}$ que:

\footnotetext{
O dever do Estado com a educação escolar pública será efetivado mediante a garantia de: inciso III - atendimento educacional especializado gratuito aos educandos com deficiência, transtornos globais do desenvolvimento e altas habilidades ou superdotação, transversal a todos os níveis, etapas e modalidades, preferencialmente na rede regular de ensino (BRASIL, 2013).
}

Desse modo, surgem as políticas públicas centradas na inclusão dos alunos com deficiência, preferencialmente, conforme pontua a Constituição Federal de 1988 no sistema de ensino regular brasileiro. 
Tem-se ainda a Lei de Diretrizes e Bases para Educação Nacional, Parâmetros Curriculares Nacionais e Diretrizes Nacionais para a Educação Especial na Educação Básica que regem a inclusão do aluno com deficiência na rede de ensino regular.

São legislações que preconizavam a igualdade de tratamento e oportunidades para todas as pessoas ao acesso à educação compartilhada com outras crianças. Propõem interação mutua entre as pessoas com e sem deficiência com acesso à convivência social e se inserir com plenitude no processo de ensino e aprendizagem.

Embora, sabe-se que o processo da história da inclusão de alunos com deficiência no ensino regular tem ocorrido de modo lento, sendo que a sociedade e as instituições de ensino estão se adequando para fazer a inclusão de fato (SANTOS; AURELIANO, 2012). Mesmo com a legislação preconizando o atendimento às pessoas com deficiência no sistema de ensino regular, há muita discussão a respeito da efetividade desta inclusão.

As escolas públicas brasileiras não contam com espaço físico adequado, recursos humanos, como profissionais qualificados, alimentação para atender o cidadão deficiente que tem direito de igualdade social, conquistado juridicamente. A maneira que o deficiente é inserido na sala de aula provoca uma situação desconfortável, constrangedora tanto para o discente quanto para o docente.

Na política de "inclusão" o professor de disciplinas raramente tem formação, perfil, aptidão para lidar com o incluído. Não é oportunizado o direito de escolha. $\mathrm{O}$ aluno deficiente é submetido a uma realidade que não é a dele, não o acolhe conforme as suas limitações especificas tanto física como psíquica emocional, cognitiva.

Para superar as atitudes de exclusão é necessária qualificação profissional, espaço físico adequado, material didático que atenda as especificidades de cada deficiência. De acordo com a Lei Brasileira de Inclusão (LBI):

\footnotetext{
Art. 15. O processo mencionado no art. 14 desta Lei baseia-se em avaliação multidisciplinar das necessidades, habilidades e potencialidades de cada pessoa, observadas as seguintes diretrizes: IV - oferta de rede de serviços articulados, com atuação intersetorial, nos diferentes níveis de complexidade, para atender às necessidades específicas da pessoa com deficiência. (BRASIL, 2015, Grifo nosso).
}

O não atendimento dos deficientes nas escolas de atendimento específico (em Minas Gerais, Goiás chamados de APAE - Associação de Pais e Amigos dos 
Excepcionais) é um dos exemplos de descaso, com a população na fase de escolarização e está presente no Art. $1^{\circ}$ da LBI

É instituída a Lei Brasileira de Inclusão da Pessoa com Deficiência (Estatuto da Pessoa com Deficiência), destinada a assegurar e a promover, em condições de igualdade, o exercício dos direitos e das liberdades fundamentais por pessoa com deficiência, visando à sua inclusão social e cidadania. (BRASIL, 2015).

A lei é pertinente e precisa do apoio da população para efetivar os direitos desses cidadãos, proporcionar a igualdade social. Porém, a realidade é que não há investimento necessário para manter a conservação dos espaços físicos, adequação das unidades escolares, além da falta de profissional preparado de acordo com a necessidade de cada deficiente.

Importante relatar que há falta de material didático, laboratório de informática funcional; internet de qualidade; xerox; livros didáticos para todos. Muitas escolas públicas têm o giz e livro didático como únicos recursos disponíveis.

As Associações de Atendimento Específicos aparentemente atendiam a LBI, que em seu texto defende que:

Art. $3^{\circ}$ III - tecnologia assistiva ou ajuda técnica: produtos, equipamentos, dispositivos, recursos, metodologias, estratégias, práticas e serviços que objetivem a funcionalidade, relacionada à atividade e à participação da pessoa com deficiência ou com mobilidade reduzida, visando à sua autonomia, independência, qualidade de vida e inclusão. (BRASIL, 2015).

Associação de Pais e Amigos dos Excepcionais custam muito aos cofres públicos por necessitarem de profissionais de várias áreas da saúde como médicos, fisioterapeutas, enfermeiros e psicólogos, assistente sociais, professores capacitados, entre outros e espaço físico adequado como quadras de esporte, piscina, anfiteatro, oficinas de artesanato, sistema de informação digital entre outras possibilidades de profissionalização dos portadores de deficiência.

A política nacional não tem a educação, o aprendizado como prioridade. $\mathrm{O}$ investimento é pouco, a verba destinada a educação não chega em tempo hábil, além dos desvios de recursos. Diante da realidade do país é relevante refletir sobre a efetivação do Art. $1^{\circ}$, da LBI que dispõem:

É instituída a Lei Brasileira de Inclusão da Pessoa com Deficiência (Estatuto da Pessoa com Deficiência), destinada a assegurar e a promover, em condições de igualdade, o exercício dos direitos e das liberdades fundamentais por pessoa com deficiência, visando à sua inclusão social e cidadania. (BRASIL, 2015). 
Ainda merece ser destacada a situação do professor de apoio que, conforme BRASIL (2005):

$\mathrm{Art}^{\circ}$ XIII - profissional de apoio escolar: pessoa que exerce atividades de alimentação, higiene e locomoção do estudante com deficiência e atua em todas as atividades escolares nas quais se fizer necessária, em todos os níveis e modalidades de ensino, em instituições públicas e privadas, excluídas as técnicas ou os procedimentos identificados com profissões legalmente estabelecidas. (BRASIL, 2015).

Na maioria, são pessoas que tem o mínimo de capacitação para acompanhar, auxiliar, reconhecer a capacidade cognitiva do discente incluso, tornando-se situações complexas para o professor de regente. Tentar interagir, relacionar com as "duas personagens" diferentes, mas que são pessoas que merecem respeito atenção.

Conforme ressaltam Papa, Viégas e Zamor (2015):

A inclusão educacional é um direito do aluno e requer mudanças na concepção e nas práticas de gestão, sala de aula e de formação de professores, para que se efetive o direito de todos à escolarização. Está fundamentado na Política Nacional de Educação Especial, na Perspectiva da Educação Inclusiva (PAPA; VIÉGAS; ZAMOR, 2015, p.01).

No Brasil é complexo o processo de igualdade social entre os sujeitos, quanto a igualdade de direitos e oportunidades, falta compromisso político e um Estado neutro que atenda e garanta os direitos civil da população, que em sua maioria não tem consciência política. Essa realidade também reflete na inclusão do aluno deficiente no sistema de educação regular.

A realidade da comunidade que possui deficiência é que as unidades escolares públicas são obrigadas a recebê-los sem as devidas adequações. Nesse sentido, Sassaki (2005) aponta seis dimensões:

Acessibilidade arquitetônica: sem barreiras ambientais físicas nos recintos internos e externos e nos transportes coletivos.

Acessibilidade comunicacional: sem barreiras na comunicação interpessoal (facea-face, língua de sinais, linguagem corporal, linguagem gestual etc.), na comunicação escrita (jornal, revista, livro, carta, apostila, etc., incluindo textos em braile, textos com letras ampliadas para quem tem baixa visão, notebook e outras tecnologias assistivas) e na comunicação virtual (acessibilidade digital). Acessibilidade metodológica: sem barreiras nos métodos e técnicas de estudo (adaptações curriculares, aulas baseadas nas inteligências múltiplas, uso de todos os estilos de aprendizagem, participação do todo de cada aluno, novo conceito de avaliação de aprendizagem, novo conceito de educação, novo conceito de logística didática, etc.), de ação comunitária (metodologia social, cultural, artística etc. baseada em participação ativa) e de educação dos filhos (novos métodos e técnicas nas relações familiares, etc.).

Acessibilidade instrumental: sem barreiras nos instrumentos e utensílios de estudo (lápis, caneta, transferidor, régua, teclado de computador, materiais pedagógicos), de atividades da vida diária (tecnologia assistiva para comunicar, 
fazer a higiene 2417 pessoal, vestir, comer, andar, tomar banho etc.) e de lazer, esporte e recreação (dispositivos que atendam às limitações sensoriais, físicas e mentais, etc.).

Acessibilidade programática: sem barreiras invisíveis embutidas em políticas públicas (leis, decretos, portarias, resoluções, medidas provisórias etc.), em regulamentos (institucionais, escolares, empresariais, comunitários etc.) e em normas de um geral.

Acessibilidade atitudinal: por meio de programas e práticas de sensibilização e de conscientização das pessoas em geral e da convivência na diversidade humana resultando em quebra de preconceitos, estigmas, estereótipos e discriminações. (SASSAKI, 2005, p. 23, grifo do autor).

Os elementos apontados por Sassaki (2005), embora estejam direcionado para atenderem o ensino universitário, são pertinentes para cumprir a Lei $\mathrm{N}^{\mathrm{o}} 13.146$, que efetiva os direitos de pessoas portadoras de deficiência que tem características de seres humanos distintos, que precisam de um olhar especial onde se observam as especificidades de limitações de cada um que requeiram os recursos de acessibilidade para atender suas necessidades especificas para que todos possam ter efetiva e plena participação e equiparação de oportunidades. Independentemente do nível de Ensino aprendizagem seja no Fundamental I, II e Médio merecem ser atendidos, resguardados os direitos conquistados. (BRASIL, 2015).

Conforme também afirmam Papa, Viégas e Zamor (2015)

Ao incluir as pessoas com deficiência, a escola se converte em ambiente mais propício à aprendizagem. Cada um é único e não existe uma fórmula geral que funcione para todos. O ritmo de aprendizagem é individual, seja da criança com deficiência, ou não. Quanto mais recursos a escola oferecer, menos limitações as crianças terão (PAPA; VIÉGAS; ZAMOR, 2015, p.01).

A inclusão escolar visa reverter o percurso de exclusão de qualquer natureza e ampliar as possibilidades de inserção de crianças, jovens e adultos em escolas regulares. Nessa perspectiva, propõe-se analisar e discutir a dinâmica e articulação entre escola, professores, pais e alunos levando em consideração a preparação da escola e do professor para lidar com a situação e ainda a interação e sociabilidades entres os alunos num todo.

\section{CONSIDERAÇÔES FINAIS}

A sociedade brasileira em alguns Estados como Minas Gerais, São Paulo e Goiás tem avançado em termo de equidade social, mas longe de atingir excelência, pois vivemos um sistema em que a elite, que domina o poder ao logo do processo não se 
preocupou em diminuir as desigualdades de direito, de distribuição de renda, de qualidade de vida.

Falar de inclusão numa sociedade que muitos não contam com saneamento básico, alimentação, sistema de saúde, água, escola, habitação, desvalorização do profissional de educação, de saúde, desemprego entre outras necessidades, faz refletir sobre o que fazer, para somar na formação de opinião, consciência política.

Ter atitude, como qualificação profissional, pode ser uma estratégia para contribuir com acessibilidade, mas sabedoria para lidar com a "inclusão", "exclusão" pode representar muito neste processo de consciência e igualdade entre os sujeitos sociais. Nesse sentido, faz-se necessário que a educação inclusiva garanta oportunidades efetivas a todos os estudantes, incluindo aqueles com deficiências por meio de atendimento adequado.

É necessário um despertar de consciência e ação para que essa inclusão não se resuma a matrícula e frequência do aluno, mas na sua integração na escola e no ensino, isto é, que ele realmente possa se sentir pertencente à escola e que desenvolva sua aprendizagem. O tema requer muitas discussões, sendo necessário sempre ser lembrado e discutido.

\section{REFERÊNCIAS}

BRASIL. Lei Brasileira de Inclusão da Pessoa com Deficiência - LBI. Disponível em: http://www.planalto.gov.br/ccivil03.htm.Acesso em: 22 de out. de 2020.

BRASIL. Agência Senado (Reprodução autorizada mediante citação da Agência Senado). Disponível em: https://www12.senado.leg.br/noticias/materias/2016/01/21/leibrasileira-de-inclusao-entra-em-vigor-e-beneficias. Acesso em: 05/07/2020.

BRASIL. Constituição da República Federativa do Brasil de 1988. Disponível em: http://www.planalto.gov.br/ccivil03//constituicao.htm. Acesso em: 22 de out. de 2020.

BRASIL. Lei $\mathbf{n}^{\circ}$ 12.796, de 4 de abril de 2013. Altera a Lei $n^{\circ} 9.394$, de 20 de dezembro de 1996, que estabelece as diretrizes e bases da educação nacional, para dispor sobre a formação dos profissionais da educação e dar outras providências. Disponível em: http://www.planalto.gov.br/ccivil_03/_ato2011-2014/2013/16.htm. Acesso em: em: 22 de out. de 2020.

BRASIL. Lei No 13.146, de 6 de Julho de 2015. Institui a Lei Brasileira de Inclusão da Pessoa com Deficiência (Estatuto da Pessoa com Deficiência); Decreto Legislativo $\mathrm{n}^{\circ}$ 186 , de 9 de julho de 2008 , em conformidade com o procedimento previsto no $\S 3^{\circ}$ do art. $5^{\circ}$ da Constituição da República Federativa do Brasil, em vigor para o Brasil, no 
plano jurídico externo, desde 31 de agosto de 2008, e promulgados pelo Decreto $\mathrm{n}^{\mathrm{o}}$ 6.949, de 25 de agosto de 2009. Disponível em: http://www.planalto.gov.br/ccivil_03/_2015-201.hhtm. Acesso em: 22 de out.de 2020.

BRASIL. Lei de Diretrizes e Bases da Educação Nacional $n^{0}$ 9.394, de 20 de dezembro de 1996. Brasília/DF: Presidência da República, 1996.

LAKATOS, E. M.; MARCONI, M. de A. Fundamentos de metodologia. 6. ed. São Paulo: Atlas, 2009.

MANTOAN, M. T. E. Inclusão escolar: o que é? Por quê? Como fazer? São Paulo: Moderna, 2003.

PAPA, F.; VIÉGAS, S. A. G.; ZAMOR, A. V. Inclusão: uma mudança no olhar da comunidade escolar para a construção de uma escola melhor inclusiva. In: Boas Práticas na perspectiva da Educação Especial Inclusiva. Volume I -2015.

SANTOS, M. do S. dos; AURELIANO, F. E. B. S. Aspectos históricos e conceituais da educação inclusiva: uma análise da perspectiva dos professores do ensino fundamental. In: Espaço do Currículo, v.4, n.2, pp.295-309, Setembro de 2011 a Março de 2012.

SASSAKI, R. K. Inclusão: o paradigma do século 21. In: Revista Inclusão. Ano I, n. 1, p. 19-23, out., 2005. 